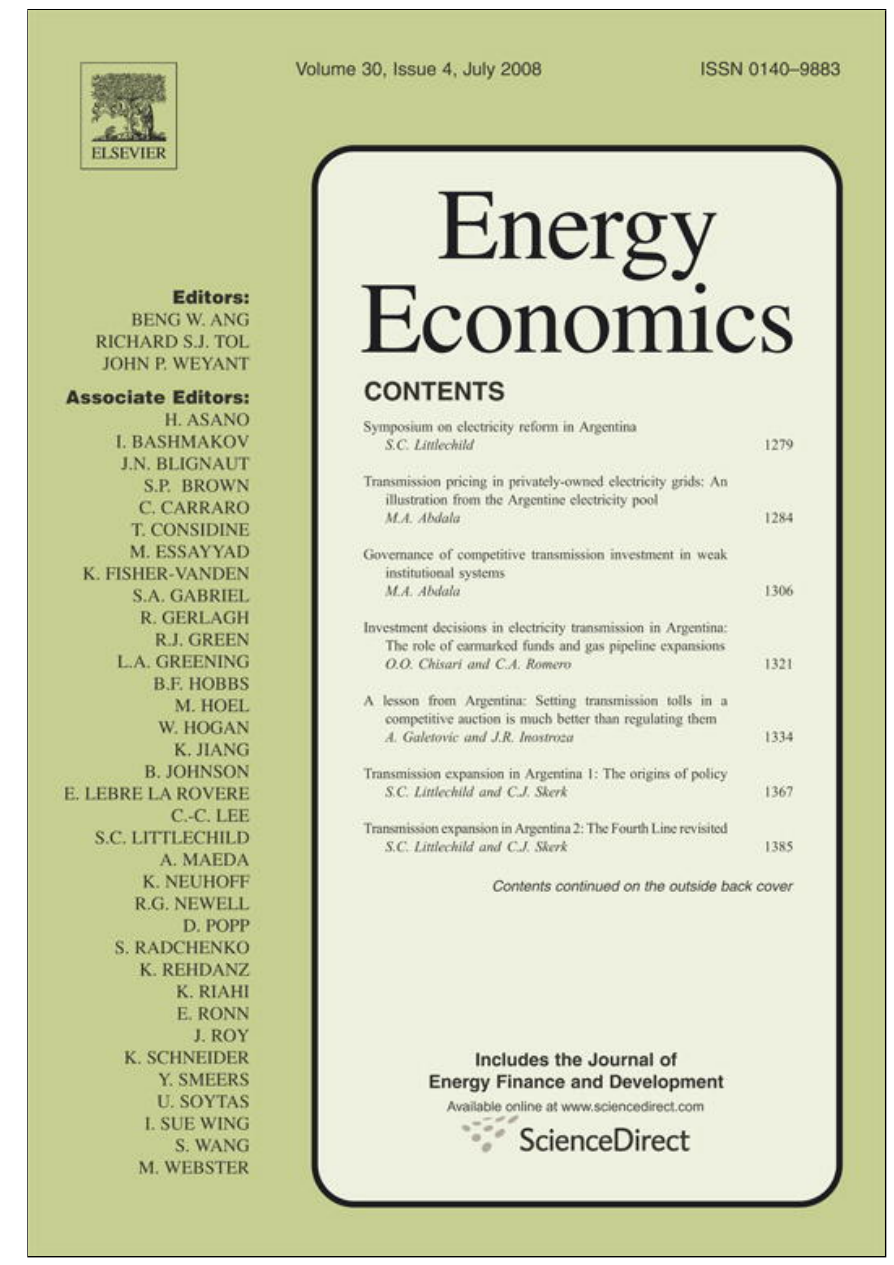

This article appeared in a journal published by Elsevier. The attached copy is furnished to the author for internal non-commercial research and education use, including for instruction at the authors institution and sharing with colleagues.

Other uses, including reproduction and distribution, or selling or licensing copies, or posting to personal, institutional or third party websites are prohibited.

In most cases authors are permitted to post their version of the article (e.g. in Word or Tex form) to their personal website or institutional repository. Authors requiring further information regarding Elsevier's archiving and manuscript policies are encouraged to visit:

http://www.elsevier.com/copyright 


\title{
European Emission Trading Scheme and competitiveness: A case study on the iron and steel industry
}

\author{
Damien Demailly, Philippe Quirion*
}

CIRED (CNRS/EHESS), 45 bis avenue de la belle Gabrielle, F 94736 Nogent sur Marne cedex, France

Received 30 August 2006; received in revised form 31 January 2007; accepted 31 January 2007

Available online 23 March 2007

\begin{abstract}
We quantify the impact of the European Emission Trading Scheme (ETS) on the two dimensions of competitiveness - production and profitability - for the iron and steel industry. Among those covered by the scheme, this sector is one of the most exposed, since it is both highly $\mathrm{CO}_{2}$-intensive and relatively open to international trade. We also examine the robustness of these results to various assumptions: marginal abatement cost curve, trade and demand elasticities, as well as pass-through rates and updating of allocation rules, of which the latter two are scarcely debated.

We conclude that for this sector, competitiveness losses are small. We prove this conclusion to be robust. Hence arguments against tightening the environmental stringency of the ETS in Phase II are not justified on grounds of competitiveness loss. Our systematic sensitivity analysis allows us to identify the important assumptions for each output variable. It turns out that pass-through rates and updating rules are significant, despite being often implicit and least debated in existing analyses.
\end{abstract}

(C) 2007 Elsevier B.V. All rights reserved.

Keywords: Iron and steel; Competitiveness; Emission trading; Greenhouse gas mitigation; Pass-through; Updating of allocation

\footnotetext{
is We would like to thank two anonymous referees, Thierry Bréchet, Jean-Charles Hourcade, Misato Sato, Henry Tulkens and participants at the 3rd CATEP workshop and CORE environmental seminar for their comments as well as the Institut français de l'énergie for financial support. The usual disclaimer applies.

* Correspoding author. CIRED (CNRS/EHESS), 45 bis avenue de la belle Gabrielle, F 94736 Nogent sur Marne cedex, France, and Laboratoire de météorologie dynamique, (LMD-IPSL), 4 Place, Jussieu, F 75252 Paris Cedex 05, France.

E-mail address: quirion@centre-cired.fr (P. Quirion).
} 


\section{Introduction}

The European GHG Emissions Trading Scheme (ETS) is the largest cap-and-trade system worldwide and the most important European climate change mitigation policy in place. Its environmental effectiveness depends on the stringency of the overall emissions cap. However, with decentralised allocation - "national allocation plans" (NAPs) submitted by each member states and reviewed by the European Commission determine national caps which aggregate to make the EU cap - the environmental stringency is indirectly controlled.

In phase I of the directive (2005-2007), the number of allowances allocated was close to, or higher than the likely business-as-usual emissions during this period (Reilly and Paltsev, 2005; Schleich and Betz, 2005). This lack of stringency is largely fuelled by concerns about the competitive disadvantage for European economies vis-à-vis non carbon-constrained countries such as the U.S. and developing countries.

The debate on industrial competitiveness is blurred, however, by loosely defined wording such as "competitive disadvantage", "competitive distortion" and "competitiveness" which can be interpreted very differently. For example, on a macroeconomic level, the very notion of competitiveness can be argued to be meaningless because exchange rates adjust over time to make up for "competitiveness distortions" experienced by a nation (Krugman, 1994). Yet on a micro level, individual industrial sectors and companies will lose or gain "competitiveness" — this can basically be reduced to two interpretations:

1. a loss in domestic production, which in turn may induce industrial relocations, domestic employment losses and possibly leakage to pollution havens;

2. a loss in profits, hence in stock value, of domestic firms.

It is essential to disentangle these two effects since, as we shall see, the ETS may impact them in very different ways.

The iron and steel industry sector is one of the most exposed among those covered by the EU ETS, since it is both highly $\mathrm{CO}_{2}$-intensive and relatively open to international trade (Quirion and Hourcade, 2004). Studies that have assessed the impact of the EU ETS in this sector (cf. Oberndorfer, 2006, and references therein) generally conclude to a modest decrease in EU production. Conversely most of these studies do not address the second aspect of competitiveness, i.e., profitability, one exception being Smale et al. (2006) who finds a positive impact.

However, these studies often do not report on the robustness of the results to the most obviously important parameters: marginal abatement cost, import, export and demand elasticities.

Debatable (and often implicit) modelling assumptions make it further problematic. First they generally do not make explicit, the rate of pass-through i.e. the share of an increase in marginal cost that is passed on to product prices. In addition, allowances are often assumed to be distributed on a lump-sum basis. As we will see, the latter assumption is not well-suited for modelling the EU ETS.

This paper assesses the impact of the EU ETS on both the production and profitability of the iron and steel sector by using a simple and transparent partial equilibrium model. Its simplicity allows us to vary key parameters and assumptions mentioned above and thus determine robustness and sensitivity of results to the different parameters. The parameters and assumptions that require more attention can therefore be identified.

We conclude that for the EU iron and steel sector in general, competitiveness losses, if any, are small. We prove this conclusion to be robust. Hence the tightening environmental stringency of 
the ETS in the second period should not be opposed on grounds of competitiveness losses. Our systematic sensitivity analysis allows us to identify important assumptions for every output variable. It turns out that the pass-through rates and updating rules, although most often implicit and not debated in existing analyses, are of major importance.

After outlining the model in the subsequent section, we present results on the competitiveness impacts of the EU ETS for central scenario in Section 3. Then, in Sections 4 and 5, we test the sensitivity of these results by varying one by one the key assumptions pre-cited. In the Following section, all assumptions are varied together to quantify the overall uncertainty. Section 7 concludes.

\section{Model}

The purpose of this paper is to build a transparent model which provides a quantitative assessment of EU ETS impacts and allows testing the robustness of the results to various assumptions: marginal abatement cost, price elasticity of demand, trade elasticities, modelling of the EU ETS allocation method and pass-through rates. The latter is determined by a given representation of competition, together with the shape of the demand and supply curves. For example, a Cournot oligopoly of $N$ identical firms with a linear demand and a flat marginal cost curve passes a share $N /(N+1)$ of an industry-wide marginal cost rise to consumers. With an isoelastic demand, firms pass through over $100 \%$ of $\mathrm{CO}_{2}$ opportunity costs to product prices. Conversely a Bertrand oligopoly leads to a zero pass-through rate if one firm is not subjected to the rise in marginal cost. In order to make the pass-through rates exogenous in our model, we do not specify the underlying assumptions on competition i.e. we do not assume a Cournot, Bertrand, or monopolistic competition. In our analysis, the pass-through rate is also independent of the shape of the demand curve. This loss of theoretical foundations is necessary to have the flexibility necessary given the aim of the paper.

In our model, the world is divided into EU 15 and the Rest of the World (RoW). We take the definition of the iron and steel sector retained by the European coal and steel community (ECSC and Eurostat, 2003), which includes only the manufacture of basic iron and steel and of ferro-alloys (NACE 27.1). In other words, we exclude the downstream activities, i.e., manufacture of cast iron and steel tubes (27.2 A and 27.2 C), first transformation of steel (27.3) and casting of iron and steel $(27.5 \mathrm{~A}, 27.5 \mathrm{C})$. Thus we retain only the most $\mathrm{CO}_{2}$-intensive and less differentiated - hence tradesensitive - part of the sector. ${ }^{1}$

For EU variables we use the subscripts $e$, for RoW variables we use the subscript $r$. In this section, we mainly present the model equations from the EU point of view but the same apply for the RoW.

\subsection{BaU conditions and competition among EU firms}

Initially, i.e. before the implementation of the EU ETS, the steel EU industry is defined by:

- a marginal production $\operatorname{cost} c_{\mathrm{e}}^{0}$, which we assume does not depend on the output level;

- a price $P_{\mathrm{ee}}^{0}$ applied by EU firms on the EU market; we assume that the same applies on non-EU market, $P_{\mathrm{er}}^{0}=P_{\mathrm{ee}}^{0}$. The gap between $c_{\mathrm{e}}^{0}$ and $P_{\mathrm{e}}^{0}$ determines the EBITDA (earnings before interests, taxes, debt and amortization) realized per tonne of steel sold by EU firms.

\footnotetext{
1 Admittedly, as suggested by an anonymous referee, trade in basic products such as pig iron and direct reduced iron might develop following an asymmetric and strong climate policy, leading to higher trade sensitivity and leakage ratio. We do not retain this possibility.
} 
- EU production $Q_{\mathrm{e}}^{0}$, which is the sum of domestic production $Q_{\mathrm{ee}}^{0}$ and export production $Q_{\mathrm{er}}^{0}$;

- EU consumption $C_{\mathrm{e}}^{0}$, which is the sum of domestic production and import $Q_{\mathrm{re}}^{0}$;

- Emissions $E_{\mathrm{e}}^{0}=Q_{\mathrm{e}}^{0} \cdot \mathrm{ue}_{\mathrm{e}}^{0}$ where ue $\mathrm{e}_{\mathrm{e}}^{0}$ is unitary emission. ${ }^{2}$

The Appendix presents the values and sources for these $\mathrm{BaU}$ variables.

\subsection{Implementation of the EU ETS}

\subsubsection{Marginal cost impact}

With the implementation of the EU ETS, the marginal cost of EU steel producers increases. The magnitude of this rise depends on:

- the $\mathrm{CO}_{2}$ price, which is assumed exogenous because the iron and steel sector amounts only to $12 \%$ of allowance allocation in the EU ETS (CDC, 2006),

- their unitary emission, $\mathrm{ue}_{\mathrm{e}}^{1}=\mathrm{ue}_{\mathrm{e}}^{0}$ - ua where ua is this unitary abatement. For a $\mathrm{CO}_{2}$ price, ua is given by a marginal abatement cost (MAC) curve,

- the rise in their electricity cost, ${ }^{3}$

- as we shall see in Section 5.2, the allocation method.

\subsubsection{Price impact}

Following an increase in marginal cost by a euro, the prices set by EU producers domestically and abroad may increase by one euro (i.e. cost pass-through rate is $100 \%$ ), by more than a euro, or less. This depends on levels of market power and international competition (see Section 5.1 below). Following econometric works, we distinguish a domestic and an export pass-through rate, the latter being generally lower: $P_{\mathrm{ee}}^{1}=P_{\mathrm{ee}}^{0}+\mathrm{PT}^{\mathrm{D}}\left(c_{\mathrm{e}}^{1}-c_{\mathrm{e}}^{0}\right)$ and $P_{\mathrm{er}}^{1}=P_{\mathrm{er}}^{0}+\mathrm{PT}^{\mathrm{X}}\left(c_{\mathrm{e}}^{1}-c_{\mathrm{e}}^{0}\right)$.

We assume that the prices set by non-EU producers are held constant.

\subsubsection{Trade}

To evaluate trade impacts, we assume the same price elasticity of imports to the EU market and to the RoW markets, $\sigma$. Given that non EU steel prices are constant, imports and exports of EU producers are driven by the two following equations:

$$
Q_{\mathrm{re}}^{1}=Q_{\mathrm{re}}^{0}\left(\frac{P_{\mathrm{ee}}^{1}}{P_{\mathrm{ee}}^{0}}\right)^{\sigma} \text { and } Q_{\mathrm{er}}^{1}=Q_{\mathrm{er}}^{0}\left(\frac{P_{\mathrm{er}}^{1}}{P_{\mathrm{er}}^{0}}\right)^{-\sigma} \text { where } \sigma>0
$$

\subsubsection{Consumption and domestic production}

To evaluate the impact on the EU consumption of the EU ETS, we define a price for EU steel consumers, $P_{\mathrm{e}}^{1}$. For simplicity sake, it is defined as the weighted sum of EU and non-EU prices (Paasche price index).

\footnotetext{
${ }^{2}$ We take into account both direct and indirect emissions, the latter being caused by electricity generation. Unitary emissions are higher for RoW than for EU (see Appendix).

${ }^{3}$ Reinaud (2004) provides unitary electric consumption for the iron and steel sector as well as electricity prices for various $\mathrm{CO}_{2}$ prices and pass-through assumptions in the power sector. We assume a 75\% pass-through in the power sector, an intermediate value in Sijm et al. (2006).
} 
Demand evolves according to the price elasticity of demand $\theta<0$, assumed constant:

$$
C_{\mathrm{e}}^{1}=\left(1-\left(1-\frac{P_{\mathrm{e}}^{1}}{P_{\mathrm{e}}^{0}}\right) \theta\right) \cdot C_{\mathrm{e}}^{0}
$$

EU domestic production is given by:

$$
Q_{\mathrm{ee}}^{1}=C_{\mathrm{e}}^{1}-Q_{\mathrm{re}}^{1}
$$

EU production is given by:

$$
Q_{\mathrm{e}}^{1}=Q_{\mathrm{ee}}^{1}-Q_{\mathrm{er}}^{1}
$$

Finally, emissions in the $\mathrm{EU}$ is $E_{\mathrm{e}}^{1}=Q_{\mathrm{e}}^{1} \cdot \mathrm{ue}_{\mathrm{e}}^{1}$.

\section{A central scenario}

\subsection{Assumptions}

This section shows the mechanisms triggered by the $\mathrm{CO}_{2}$ price for a single set of parameters and modelling assumptions. The parameters (MAC curve parameters, price elasticity of demand $\theta$, price elasticity of imports and exports $\sigma$, domestic and export pass-through rates $\mathrm{PT}^{\mathrm{X}}$ and $\mathrm{PT}^{\mathrm{D}}$ ) are intermediate values taken from the literature. For modelling of the allocation method, we use the most common practice labelled "no updating"; we assume that the allocation in a given 5-year period does not depend on firms' behaviour in previous periods.

Under the "no updating assumption", the profit of an EU firm on the EU market ${ }^{4}$ in an allocation period is:

$$
\Pi_{q, \text { ua }}=P_{\mathrm{ee}} \cdot q_{\mathrm{ee}}-c_{\mathrm{e}}(\mathrm{ua}) q_{\mathrm{ee}}-P_{\mathrm{CO}_{2}} \cdot q_{\mathrm{ee}} \cdot \text { ue }+P_{\mathrm{CO}_{2}} \cdot \mathrm{LS}-F
$$

where $q_{\mathrm{ee}}$ is the production of an EU firm sold at home, LS is its lump-sum allocation and $F$ the fixed production cost, assumed constant thereafter.

Profit maximisation leads to the first-order conditions:

$$
\begin{aligned}
& \frac{\mathrm{d} c_{\mathrm{e}}}{\mathrm{dua}}=P_{\mathrm{CO}_{2}} \\
& P_{\text {ee }}+\frac{\mathrm{d} P_{\mathrm{ee}}}{\mathrm{d} q_{\mathrm{ee}}} q_{\text {ee }}=c_{\mathrm{e}}(\text { ua })+P_{\mathrm{CO}_{2}} \cdot \mathrm{ue}_{\mathrm{e}}
\end{aligned}
$$

Unsurprisingly, without updating firms equalize their marginal abatement cost with the $\mathrm{CO}_{2}$ price and, in their production decision, add to their marginal production cost the opportunity cost of emissions, in spite of the fact that they receive allowances for free. ${ }^{5}$

MAC curves (hereafter MACCs) are second-degree polynomials fitted to results from the Primes partial equilibrium model (Blok et al., 2001). This has been widely used to study the EU

\footnotetext{
${ }^{4}$ Similar equations apply to the RoW market.

${ }^{5}$ Under BAU, $P_{\mathrm{ee}}+\frac{\mathrm{d} P_{\mathrm{ee}}}{\mathrm{d} q_{\mathrm{ee}}} q_{\mathrm{ee}}=c_{\mathrm{e}}(0)$ and $\frac{\mathrm{d} c_{\mathrm{e}}}{\mathrm{dua}}=0$.
} 
Table 1

Results of the central scenario

\begin{tabular}{llll}
\hline$\Delta c_{\mathrm{e}}$ & $+6 \%$ & $\Delta C_{\mathrm{e}}$ & $-0.5 \%$ \\
$\Delta P_{\mathrm{ee}}$ & $+2.5 \%$ & $\Delta$ EBITDA $_{Q}$ & $+1.5 \%$ \\
$\Delta Q_{\mathrm{er}}$ & $-2 \%$ & $\Delta E_{\mathrm{e}}$ & $-12 \%$ \\
$\Delta Q_{\mathrm{re}}$ & $+2.5 \%$ & CRFA & $57 \%$ \\
$\Delta Q_{\mathrm{e}}$ & $-1 \%$ & Leakage & $5 \%$ \\
\hline
\end{tabular}

climate policy and turns out to be intermediate as regards the abatement ability of the iron and steel sector (cf. Section 4.1 below).

We assume a price elasticity of demand $\theta$ of -0.3 for the total demand for steel, which is then divided between domestic and foreign competitors. We use values taken from Winters (1995) which have been applied by Maestad (OECD, 2002). Gielen and Moriguchi (2002) and Hidalgo et al. (2003) take a very similar price elasticity of -0.2 .

Price elasticities of imports and exports $\sigma$ are computed using the dataset from Kee et al. (2004).

Concerning domestic and export pass-through rates, although indicated in the empirical literature for some sectors (Stennek and Verboven, 2001), to our knowledge, this is not the case for the EU steel sector in the EU ETS context. Moreover, the figures provided in the literature for other sectors are much above the expectations of experts or industrials. As such, for the domestic pass-through rate, we apply the methodology developed for a UK cross-sectoral analysis by Smale et al. (2006). This derives $75 \%$ pass-through for the EU steel sector, an intermediate value between industrial assertions and the previous literature. A notable interest of this methodology is that it had been previously used by the authors in a study realized in collaboration with industrials (Oxera, 2004). Export pass-through being lower than domestic pass-through (Stennek and Verboven, 2001), we assume a $50 \%$ pass-through rate for the non-EU market.

\subsection{Results}

As demonstrated by the volatile price of EU ETS allowances since its implementation, the $\mathrm{CO}_{2}$ price is highly uncertain. Thus, we run the model for a $\mathrm{CO}_{2}$ price from 0 to 50 euros per ton of $\mathrm{CO}_{2}$. Throughout the paper, in most cases, we present the expected impact, assuming that the $\mathrm{CO}_{2}$ price follows a Gamma probability distribution with a mean of 20 euros (the price of futures contracts for 2008-2012 allowances, according to European Climate Exchange, July 2006) and a

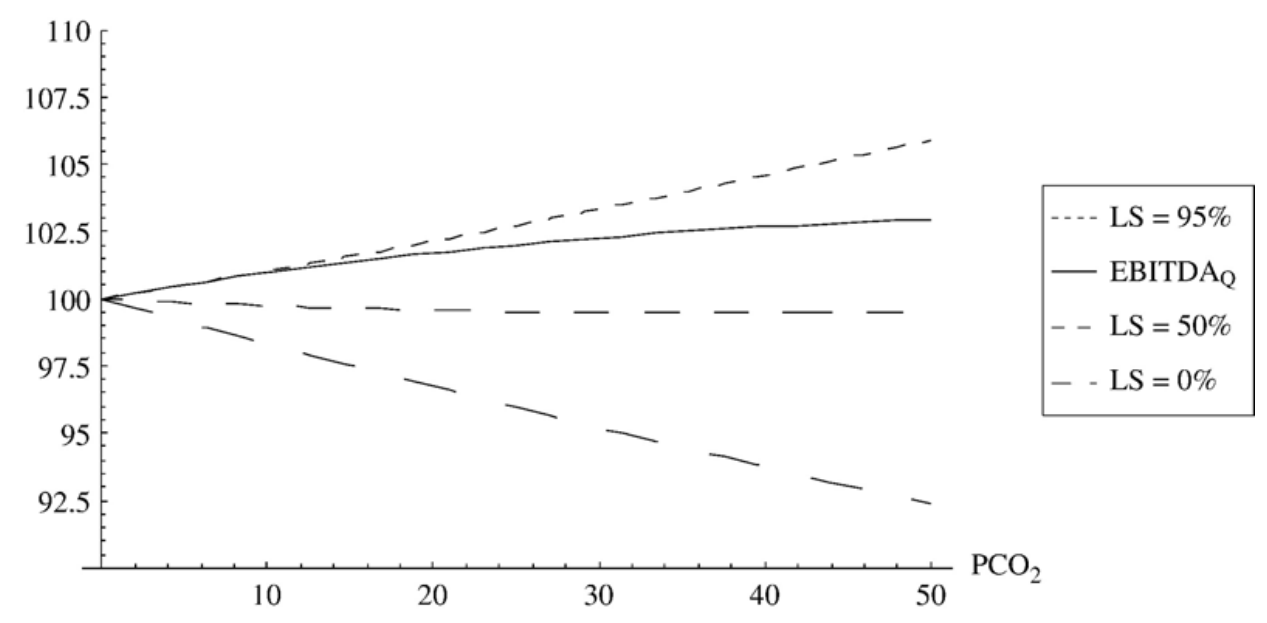

Fig. 1. EBITDA in the Central scenario. 
variance of 40 (the variance of $\mathrm{ECX} \mathrm{CO}_{2}$ prices from January to July 2006). We present the impact as a function of the $\mathrm{CO}_{2}$ price only in a few cases.

As Table 1 shows, the rise in marginal cost $\Delta c_{\mathrm{e}}$ is $6 \%$, of which $70 \%$ being due to the opportunity cost, $26 \%$ to the electricity cost rise and only $4 \%$ to the abatement cost. However, because the marginal cost accounts for only half of the steel price, the increase in home price $P_{\text {ee }}$ is small, in spite of an important pass-through. Overall impact on imports, exports, consumption and production are limited. This conclusion on the first aspect of competitiveness is in line with other assessments (see references above).

EBITDA of the EU producers is defined as follows:

$$
\text { Ebitda }_{\mathrm{e}}=P_{\mathrm{ee}} \cdot Q_{\mathrm{ee}}+P_{\mathrm{er}} \cdot Q_{\mathrm{er}}-c_{\mathrm{e}}(\mathrm{ua}) Q_{\mathrm{e}}+P_{\mathrm{CO}_{2}}\left(\mathrm{LS}-Q_{\mathrm{e}} \cdot \mathrm{ue}\right)
$$

The last part of this equation is the profit or loss realised by EU steel producers on the $\mathrm{CO}_{2}$ market. We label the rest of the equation "EBITDA on production" (EBITDA $\left.{ }_{Q}\right)$. This is EBITDA realised on the steel market. As Fig. 1 shows, EBITDA ${ }_{\mathrm{Q}}$ increases with the $\mathrm{CO}_{2}$ price. Here, the rise in steel price, mostly due to the opportunity cost of allowances, is more than offset by the effect of a slight decrease in output. The expected EBITDA on production rises by $1.5 \%$.

Emissions in the iron and steel sector covered by the EU ETS drop by $12 \%$, of which only $9 \%$ is due to the decrease in production and $91 \%$ to the drop in emissions intensity. The position of steel producers on the $\mathrm{CO}_{2}$ market is highly sensitive to allocation. On the following graph, we plot, as a function of the $\mathrm{CO}_{2}$ price, the EBITDA for various levels of free allocation, expressed as a percentage of $\mathrm{BaU}$ emissions. The difference between each dashed line and EBITDA on production $\left(\mathrm{EBITDA}_{\mathrm{Q}}\right)$ gives the profit or loss on the $\mathrm{CO}_{2}$ market.

As shown by the bottom curve, a $\% \%$ free allocation entails a significant loss of EBITDA, which increases with the $\mathrm{CO}_{2}$ price. This is the rationale for allocating for free at least a part of the allowances. On the other hand, a 95\% free allocation overcompensates EBITDA loss; the expected total EBITDA increases by $2 \%$. Throughout the paper, we label "compensating rate of free allocation" (CRFA), the ratio required to keep expected EBITDA steady. ${ }^{6}$ It equals $57 \%$ in the central scenario, much less than the level of free allocation in all existing NAPs. It is worth noting that roughly speaking, allocating half of $\mathrm{BaU}$ emissions for free maintains EBITDA whatever the price of $\mathrm{CO}_{2}$.

Another way to compensate EBITDA loss when allowances are auctioned is to rebate a part of auctioning revenue back to firms. It is equivalent to give let us say $50 \%$ of allowances for free or to rebate $50 \%$ of the revenue. Therefore, CRFA may be interpreted as the share of BaU emissions which have to be given for free to maintain EBITDA, or as the share of the auction revenue which has to be rebated.

Putting aside competitiveness impacts and turning to the environmental effectiveness of the ETS, we compute the leakage rate (increase in emissions abroad divided by emissions reduction in the UE). Indeed, the loss of market shares by EU producers induces an increase in emissions abroad. $^{7}$ The leakage rate equals $5 \%$, in the lower bound of the range of economy-wide leakage

\footnotetext{
${ }^{6}$ Maintaining EBITDA steady is equivalent to maintaining profit steady if we assume that capital is identical across the $\mathrm{BaU}$ and climate policy scenarios. CRFA would be lower if one assumes that capital may adjust, which is likely if their is a clear long-term signal on the $\mathrm{CO}_{2}$ price.

7 This leakage rate takes into account indirect emissions due to the generation of electricity consumed by iron and steel production in the EU and abroad. However, more leakage may occur if EU producers increase their use and net imports of scrap, raising scrap prices and reducing the use of scrap in steel making abroad (OECD, 2002).
} 


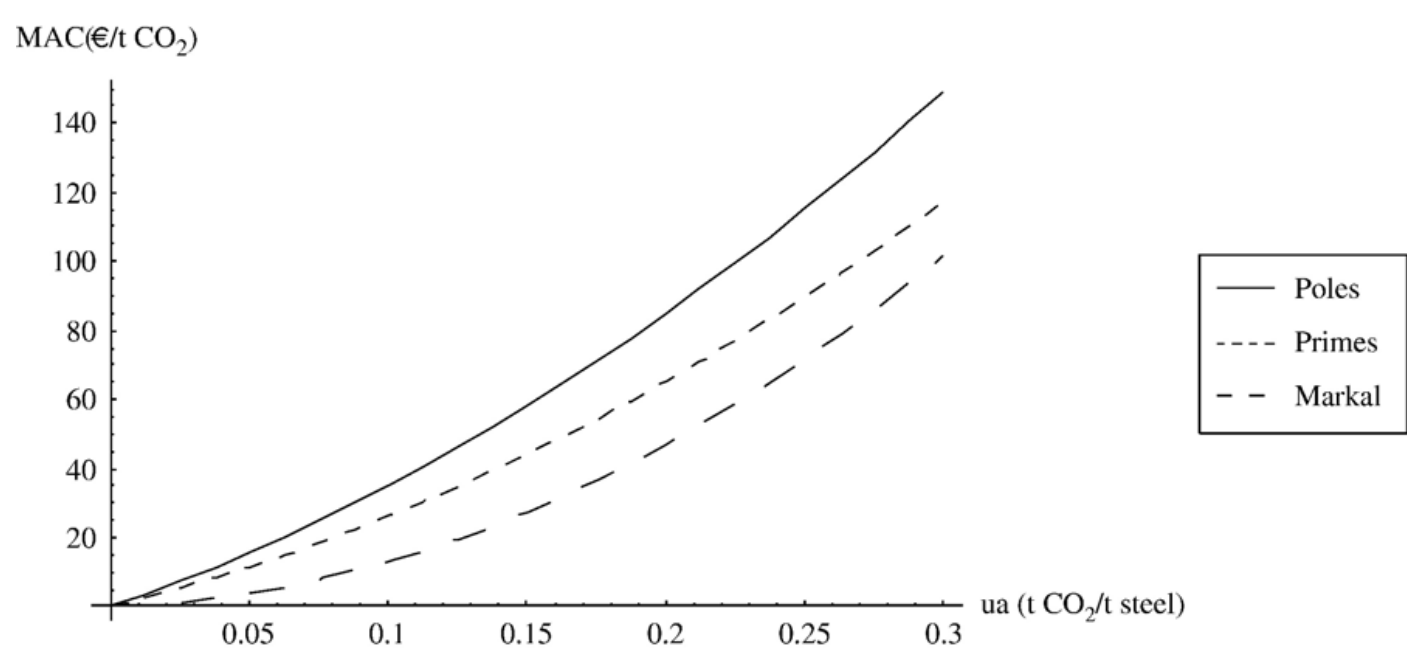

Fig. 2. MACCs.

estimates of 5 to $20 \%$ presented in the IPCC third assessment report (cf. Hourcade and Shukla, 2001). ${ }^{8}$ The iron and steel sector does not seem especially sensitive to $\mathrm{CO}_{2}$ leakage. However the robustness of this qualitative result, as well as the previous ones, has to be challenged. To this we turn in the following two sections.

\section{Sensitivity to classical parameters}

In the Subsections 4.1-4.3, we will vary sequentially the most obviously important parameters: MAC curve parameters, price elasticity of demand $\theta$, and price elasticity of imports and exports $\sigma$.

\subsection{Marginal abatement cost curves}

As explained above, in the central scenario, the MACC is fitted from the Primes model. In this subsection, we assess the importance of this assumption by using MACCs fitted from two other models: Markal Europe (Sijm et al., 2002), which is the more optimistic, and Poles (Kitous, 2002), which is the more pessimistic. The figure above (Fig. 2) represents the three MACCs.

The figure below (Fig. 3) displays the impact of the EU ETS on key variables, for the three MACCs, as a percentage of variation compared to BaU. To improve the readability of the graph, results for CRFA are divided by ten.

Clearly, the MACC assumption does not impact price. This is due to several reasons. First the rise in marginal cost is fairly robust, due to the robustness of its main component, the opportunity cost. Second, the marginal cost represents only half of the price, so that the gap between relative increases in price is also halved compared to marginal cost.

Since the price increase is robust, so are production and EBITDA on production.

Conversely the main fuel for emissions reduction, i.e. unitary abatement, varies by a factor of around two, as we see in Fig. 2, which leads abatement to vary by the same amount. Thus we could expect CRFA to be sensitive to the MACC assumption. Yet it is not the case because higher unitary emissions entail a slightly higher opportunity cost hence a slightly higher EBITDA on

\footnotetext{
${ }^{8}$ Most of these leakage estimates are produced by General Equilibrium models, which do not feature a detailed iron and steel sector, but which take into account other leakage channels that the loss in market share, in particular the drop in world fuel prices (Sijm et al., 2004). That is why our results may only be compared cautiously to these estimates.
} 


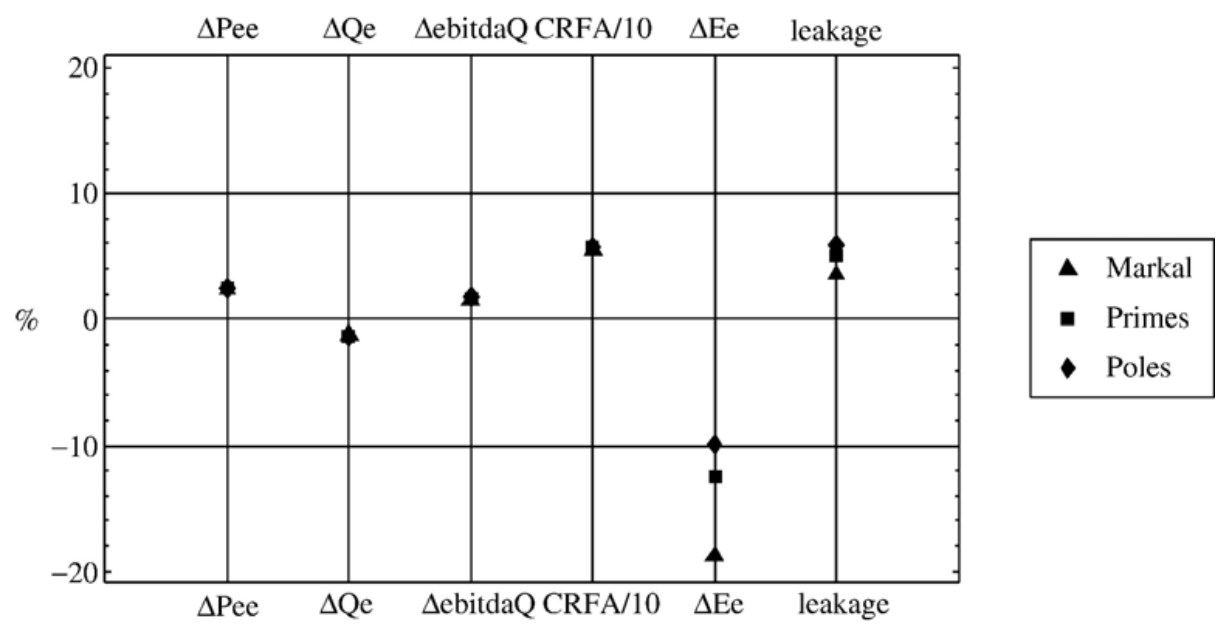

Fig. 3. EU ETS impacts for various MACC assumptions.

production, which compensates the deterioration of the position of steelmakers on the $\mathrm{CO}_{2}$ market. Moreover, EBITDA on production turns out to be the core part of total EBITDA, hence CRFA is driven mostly by EBITDA on production and only marginally by emissions reduction. This is true throughout the paper.

Concerning environmental effectiveness, the leakage rate goes from 3.5\% for the Markal MACC to $6 \%$ for the Poles MACC but remains close to the lower bound of the range of economywide estimates. This factor of around two mimics the variability of emissions reductions.

\subsection{Price elasticity of demand}

A brief review of the literature on the price elasticity of demand for steel leads to an upper value of - 0.62 (Lord and Ken Farr,w 2003). For the lower value, we choose zero to take into account the fact that although steel demand may decrease in some applications, steel may win some market shares vis-à-vis more $\mathrm{CO}_{2}$-intensive materials also covered by the EU ETS, especially cement.

Unsurprisingly, this assumption does not impact steel price (Fig. 4). The drop in EU production varies from $-0.5 \%$ (inelastic demand) to $-2 \%$ (high elasticity of demand): although the price elasticity of demand assumption entails a significant variability in production drop

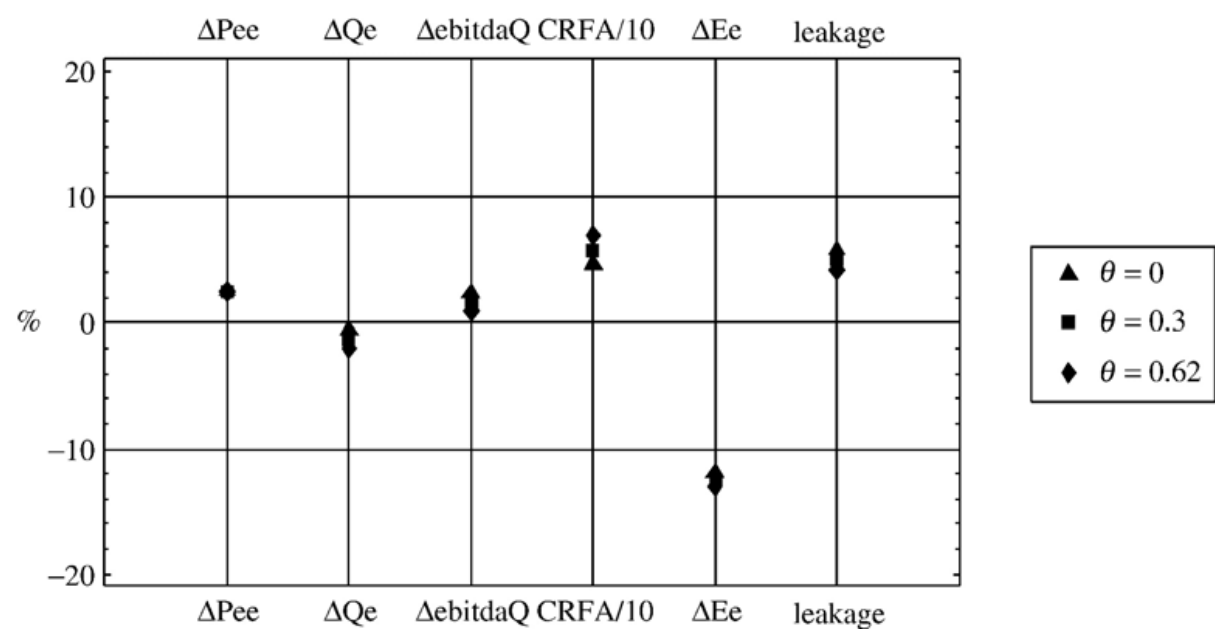

Fig. 4. EU ETS impacts for various assumptions on the price elasticity of demand. 
(more important than all other assumptions as we will see), the drop remains fairly low. The variability in EBITDA on production and therefore in CRFA is significant. Finally, since, as seen previously, the reduction in total emissions is mostly due to the drop in unitary emissions and not to the drop in production, the impact of the price elasticity of demand on emissions and leakage is weak.

\subsection{Price elasticity of imports and exports}

A review of the literature on price elasticity of imports and exports for the iron and steel sector leads an upper value of 3.3 (cf. Erkel-Rousse and Mirza, 2002, and references therein) and a lower value of 0.55 (cf. Fouquin et al., 2001).

This assumption does not impact the price (Fig. 5). It quite significantly impacts the drop in production and the increase in EBITDA on production, However, the production drop remains fairly limited in all cases: from $1 \%$ to $2.5 \%$. The increase in EBITDA on production goes from $0.5 \%$ to $2 \%$ : even for high import elasticity, EU producers' EBITDA on production rises.

The impact of this assumption on emissions is limited, which is once again due to the fact that the bulk of emissions reduction comes from unitary abatement.

What about the CRFA? On the one hand, the slightly higher emissions reduction in the high elasticity case improves the position of steel makers on the $\mathrm{CO}_{2}$ market. On the other hand the EBITDA on production raises less. The latter effect dominating, more allowances have to be allocated for free to the iron and steel sector in this case: the CRFA reaches almost $80 \%$.

Conversely, leakage occurring only through the trade channel in our model, it is highly impacted by the calibration of imports price elasticity: from $2 \%$ to $15 \%$, the highest variability observed. In spite of that, the leakage rate of the iron and steel sector does not overcome the upper bound of economy-wide leakage estimates.

\section{Sensitivity to key modelling choices}

Having checked the robustness of our results to the most obvious parameters, we now test the impact of often implicit yet debatable modelling assumptions: the pass-through rates and the allocation of allowances.

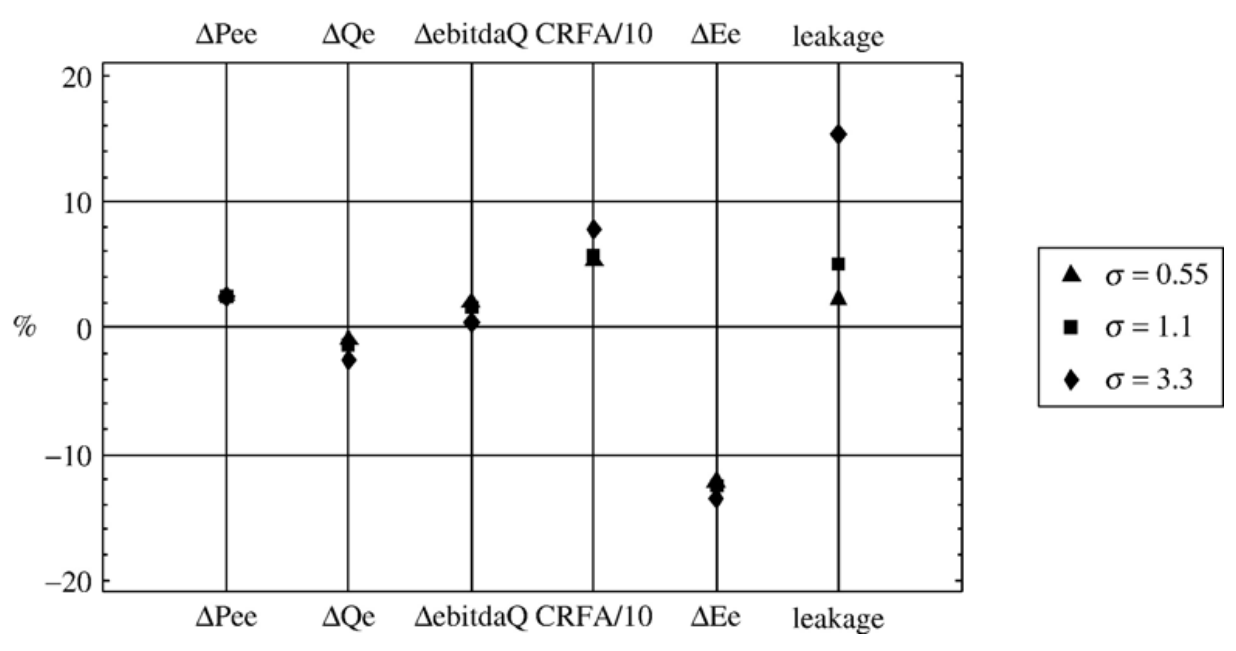

Fig. 5. EU ETS impacts for various assumptions on the price elasticity of trade. 

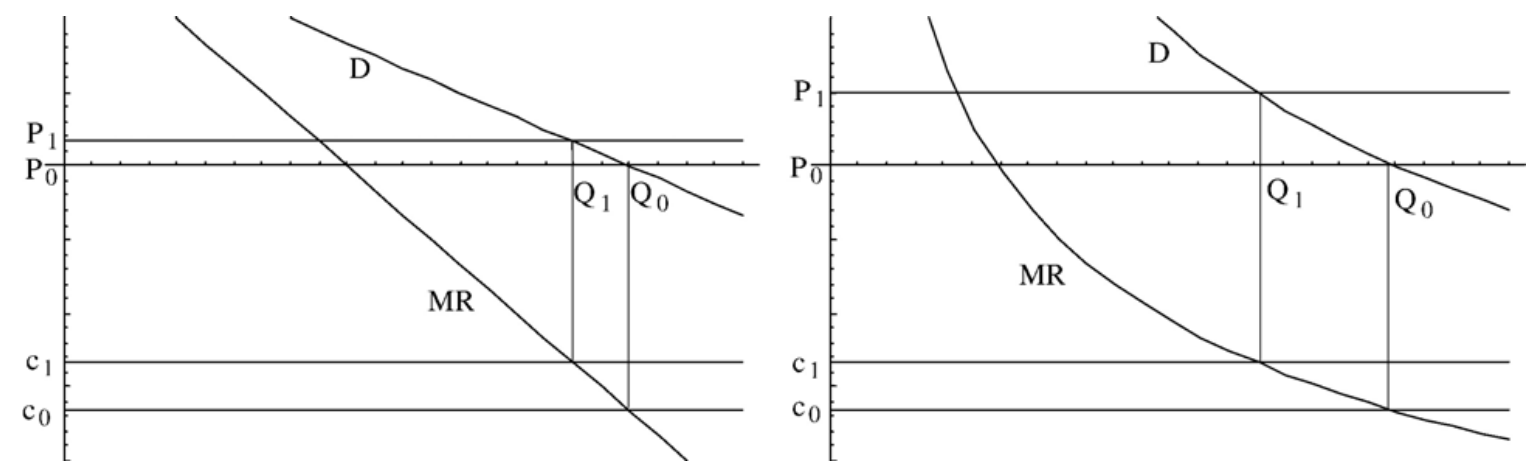

Fig. 6. Role of the shape of the demand curve in the pass-through of a monopoly. Left: linear demand curve, right: isoelastic demand curve. Both panels feature the same elasticity hence the same mark-up at the initial equilibrium $\left(P_{0}, Q_{0}\right)$.

\subsection{Pass-through}

As explained above, contrary to the previous assumptions, the pass-through rate is generally not explicit in applied models. ${ }^{9}$ In our model, we make this assumption explicit because, as we shall see, it is of the utmost importance for the competitiveness issue. Theoretical work has shown that the pass-through rate depends:

$\Rightarrow$ on the shape and elasticity of the demand curve,

$\Rightarrow$ on the elasticity of the supply curve,

$\Rightarrow$ on the nature and intensity of competition among firms subjected to the rise in marginal cost (the higher the market power, the lower the pass-through),

$\Rightarrow$ on the nature and intensity of competition between these firms and those not subjected to the rise in marginal cost (especially foreign firms).

In particular, the shape of the demand curve (linear or isoelastic) is often seen as a neutral assumption whereas it has a dramatic impact on the induced pass-through rate, as we may see in the monopoly case with a flat marginal cost curve on the graph above (Fig. 6).

This figure represents the basic model of a monopoly: the firm chooses an output level by equalising the marginal receipt (MR) and marginal production cost $(c)$ curves, and the price results from the demand curve $(D)$ for this quantity. We suppose that the marginal cost rises from $c_{0}$ to $c_{1}$. On the left panel, featuring a linear demand curve, the output price rises by half the rise in marginal cost whereas on the right panel, with an isoelastic demand curve, this monopolist maintains its relative mark-up $(P-c) / c$ and passes more than $100 \%$ of its marginal cost increase.

Leaving aside theoretical considerations, what would be the order of magnitude of the export and domestic pass-through in the EU steel sector, given its openness to international trade and its oligopolistic nature? An empirical study would be required to answer such a question. To our knowledge, such a study has not yet been conducted. Moreover, as we have seen previously, there is an important gap between experts or industrials expectations and the empirical literature on excise tax or exchange rate pass-through we could rely on. Finally, we take 50 and $100 \%$ as extreme values for the domestic pass-through, and 25 and $75 \%$ for the export pass-through. Such ranges are obviously debatable, which is a first claim for further investigation on that topic.

\footnotetext{
${ }^{9}$ An exception being Smale et al. (2006).
} 


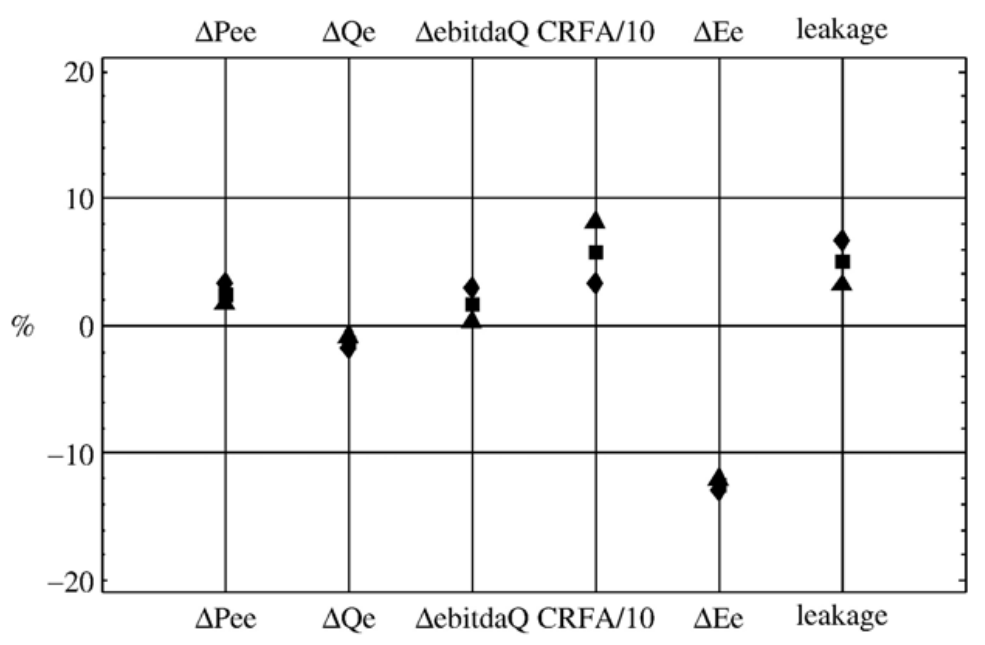

\ $\mathrm{PTd}=50, \mathrm{PTx}=25$

- $\mathrm{PTd}=75, \mathrm{PTx}=50$

PTd $=100$, PTx $=75$

Fig. 7. EU ETS impacts for various assumptions on pass-through values.

The impact of the ETS on steel price differs by a factor of two between the two extreme cases the most important variability - but remains limited (from +1.5 to $+3 \%$ ) (Fig. 7). So is the impact on production (from $-1 \%$ to $-2 \%$ ). EBITDA on production is more sensitive since it differs by a factor of six: from $+0.5 \%$ for low pass-through rates to $+3 \%$ for the high ones. The pass-through assumption yields a high variability in EBITDA on production. As a consequence, the compensating rate of free allocation features the highest variability: from 35 to $80 \%$.

We stress that here again, the evolution of EBITDA on production remains positive for every assumption and that the CRFA remains well below the NAPs in place and expected in the near future. It is worth noting that the pass-through assumption has an opposite effect on the two aspects of competitiveness: a higher pass-through entails a higher EBITDA but lower market shares, and vice-versa.

Emissions reduction is not sensitive to the assumption on pass-through. The pass-through assumption influencing imports and exports, causes the leakage rate to differ by a factor two $(+3$ to $+7 \%$ ), yet it remains close to the lower bound of the range of economy-wide estimates.

\subsection{Modelling of the EU ETS allocation method}

In the previous section we have seen to what extent competitiveness impacts of the EU ETS depend on the pass-through of the marginal cost rise. Here we have assumed it is profitmaximising for a firm to include the opportunity cost of emissions in its marginal cost, as though firms had to buy their allowances through an auction. This assumption holds if we neglect the immaturity of the carbon market and if we suppose optimal behaviour, i.e. firms pursue profitmaximisation, which is debatable (Smale et al., 2006). Even under these conditions, this assumption depends on the allocation method. As we have seen, it holds under lump-sum free allocation. Most assessments of the EU ETS make this assumption (e.g. Bernard et al., 2006; Böhringer et al., 2006; Klepper and Peterson, 2004, 2006; Reilly and Paltsev, 2005). However, it applies well to the US $\mathrm{SO}_{2}$ trading system, but much less to the EU ETS, mainly because of updating: allowances are first allocated for a 3-year period (2005-2007), and then every 5 years, taking into account new information. ${ }^{10}$

\footnotetext{
${ }^{10}$ Other reasons are free allowances for new installations and the fact that closing installations will stop receiving allowances (Åhman et al., 2005; Schleich and Betz, 2005).
} 
Thus, during a given phase of the ETS, a firm may well expect to receive fewer allowances in the subsequent periods if it reduces its emission or production. Such an expectation is rational for example in France, since in the NAP proposal for 2008-2012 (France and MEDD, 2006) the amount of allowances a sector gets depends on its production and unitary emissions up to 2005, i.e., during the first phase of the EU ETS. Since in the biggest sectors, there is a dominant firm (EDF for power generation, Lafarge for cement, Arcelor-Mittal for steel...), the latter may be reluctant to cut their emissions and production.

Thus, the competitiveness impacts of the ETS may be significantly modified by the expectations of firms about the updating rules. As we have seen, in the central scenario, we assume no updating, i.e., the number of free allowances a firm gets in period $t$ is independent to its behaviour in previous periods. This leads firms to equalize their marginal abatement cost with the $\mathrm{CO}_{2}$ price and, in their production decision, to add to their marginal production cost the opportunity cost of emissions.

In this section, we consider two other updating rules, which are likely to be adopted by Member States or expected by firms: 'emission-based (EB) updating' and 'output-based (OB) updating'.

\subsubsection{Output-based $(O B)$ updating}

Under OB updating, the allocation a firm gets in a period $t$ equal its production in period $t-1$ multiplied by an emission rate ob. This rate is independent on firm's behaviour and decreases every period by a given rate $s \in[0,1], s$ for stringency:

$$
\mathrm{LS}^{t}=Q_{\mathrm{e}}^{t-1} \cdot \mathrm{ob}(1-s)
$$

Then the discounted sum of its profit is: ${ }^{11,12}$

$$
\begin{aligned}
\Pi_{q_{\mathrm{ee}}, \text { ua }}= & P_{\mathrm{ee}} q_{\mathrm{ee}}+P_{\mathrm{er}} q_{\mathrm{er}}-c_{\mathrm{e}}(\text { ua }) q_{\mathrm{e}}-P_{\mathrm{CO}_{2}} q_{\mathrm{e}} \cdot \mathrm{ue}+P_{\mathrm{CO}_{2}} \mathrm{LS}^{1}-F \\
& +\sum_{n=1}^{\infty}(1-\tau)^{5 n}\left(P_{\mathrm{ee}} q_{\mathrm{ee}}+P_{\mathrm{er}} q_{\mathrm{er}}-c_{e}(\text { ua }) q_{\mathrm{e}}-P_{\mathrm{CO}_{2}} q_{\mathrm{e}} \cdot\right. \text { ue } \\
& \left.+P_{\mathrm{CO}_{2}} q_{\mathrm{e}} \cdot \mathrm{ob}(1-s)^{n}-F\right)
\end{aligned}
$$

where $\tau \in[0,1]$ is the discount rate and $F$ represents fixed costs. Then, the first order conditions of the profit maximisation are:

$$
\begin{aligned}
& \frac{\mathrm{d} c_{\mathrm{e}}}{\mathrm{dua}}=P_{\mathrm{CO}_{2}} \\
& P_{\mathrm{ee}}+\frac{\mathrm{d} P_{\text {ee }}}{\mathrm{d} q_{\mathrm{ee}}} q_{\mathrm{ee}}=c_{\mathrm{e}}(\text { ua })+P_{\mathrm{CO}_{2}(\text { ue }-\Theta \cdot \text { ob })}
\end{aligned}
$$

where $\Theta=\left(1-(1-\tau)^{5}\right) \frac{(1-\tau)^{5}(1-s)}{1-(1-\tau)^{5}(1-s)}, \Theta \in[0,1]$.

\footnotetext{
11 We did not discount profits in the central scenario because this would not change the first-order conditions.

${ }^{12}$ We notably assume a constant $\mathrm{CO}_{2}$ price in spite of the expected increasing stringency of the overall allocation. However, for a not too high value of $s$ and a discount rate high enough, the impact of this assumption may not be significant.
} 
Compared with no updating, firms do not add all the opportunity cost of their emissions to their marginal cost - and therefore produce more in order to receive more allowances in subsequent periods.

\subsubsection{EB updating}

Under EB updating, the allocation of free allowances a firm gets in a period $t$ equals its emission in period $t-1$ minus a rate $s$ :

$$
\mathrm{LS}^{t}=Q_{\mathrm{e}}^{t-1} \cdot \mathrm{ue}^{t-1}(1-S)
$$

Then, the discounted sum of its profits is:

$$
\begin{aligned}
\Pi_{q_{\mathrm{ee}}, \text { ua }}= & P_{\mathrm{ee}} q_{\mathrm{ee}}+P_{\mathrm{er}} q_{\mathrm{er}}-c_{\mathrm{e}}(\text { ua }) q_{\mathrm{e}}-P_{\mathrm{CO}_{2}} q_{\mathrm{e}} \cdot \text { ue }+P_{\mathrm{CO}_{2}} \mathrm{LS}^{1}-F \\
& +\sum_{n=1}^{\infty}(1-\tau)^{5 n}\left(P_{\mathrm{ee}} q_{\mathrm{ee}}+P_{\mathrm{er}} q_{\mathrm{er}}-c_{\mathrm{e}}(\text { ua }) q_{\mathrm{e}}-P_{\mathrm{CO}_{2}} q_{\mathrm{e}} \cdot\right. \text { ue } \\
& \left.+P_{\mathrm{CO}_{2}} q_{\mathrm{e}} \cdot \mathrm{ue}(1-s)^{n}-F\right)
\end{aligned}
$$

Profit maximisation leads to the following first order conditions:

$$
\begin{aligned}
& \frac{\mathrm{d} c_{\mathrm{e}}}{\mathrm{dua}}=P_{\mathrm{CO}_{2}}(1-\Theta) \\
& P_{\mathrm{ee}}+\frac{\mathrm{d} P_{\mathrm{ee}}}{\mathrm{d} q_{\mathrm{ee}}} q_{\mathrm{ee}}=c_{\mathrm{e}}(\text { ua })+P_{\mathrm{CO}_{2}} \mathrm{ue}(1-\Theta)
\end{aligned}
$$

The second equation is equivalent to the second first-order condition under OB updating. ${ }^{13}$

Moreover, where firms are able to influence the unitary allocation in future periods, they have an incentive to reduce their initial abatement effort.

Finally, the expectation of an OB or EB updating notably leads firms to only add some share of the emission opportunity cost to their marginal costs. In this subsection, we take $\tau=10 \%$ and $s=5 \%$, which are "reasonable" assumptions and lead to $\Theta=0.5$ : only half of the opportunity cost is added to the marginal cost.

We stress that in the previous subsections, the central scenario yields medium results because its features medium values for parameters. Conversely, the no updating assumption is not "central", in the sense that it creates a higher incentive to reduce production and emissions compared with the two alternatives.

Compared to the central scenario (no updating), both updating rules reduce the competitiveness impacts of the ETS: the drop in production is almost halved, the rise in EBITDA on production is divided by around 5 and variability is as high as with the pass-through assumption (Fig. 8). Although they do not lead to the highest variability in CRFA, they induce the highest CRFAs: $83 \%$ under OB updating and $85 \%$ under EB updating instead of $57 \% .{ }^{14}$ The small difference between $\mathrm{OB}$ and $\mathrm{EB}$ updating is due to the fact that emissions reduction is halved in the latter case - hence the position on the $\mathrm{CO}_{2}$ market worsens. Emissions reduction under OB updating is only slightly less than under no updating, once again because they are above all fuelled by unitary abatement.

\footnotetext{
${ }^{13}$ If the iron and steel sector is neither a net buyer nor a net seller, then $\mathrm{ob}=$ ue and the price setting rules under $\mathrm{OB}$ updating and $\mathrm{EB}$ updating are equivalent.

${ }^{14}$ Figures for CRFA under updating are overestimated since we assume that firms expect that their behaviour influences the amount of allowances grandfathered (which is fair) but also the amount of allowances auctioned (which is not).
} 

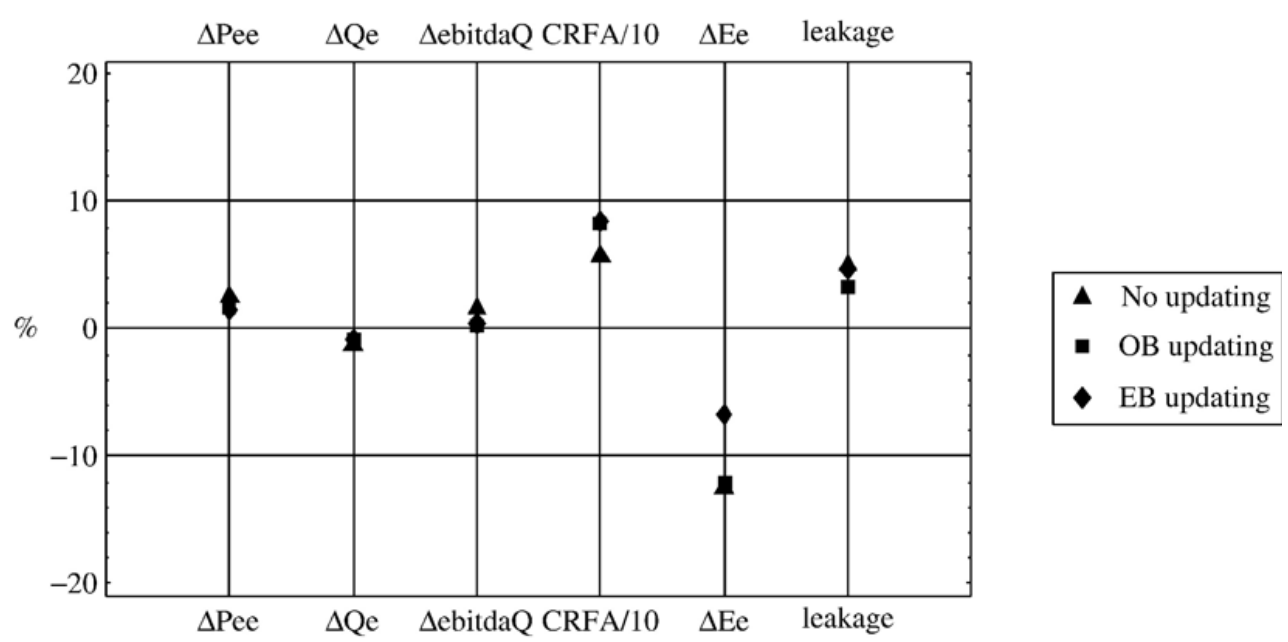

Fig. 8. EU ETS impacts for various assumptions on the updating rules of allocation.

The leakage rate is lower under OB updating (3\%) compared to no updating (5\%), where the former softens the international trade impact of the ETS. It is intermediate under EB updating (4.5\%), the latter effect being almost compensated by the drop in unitary abatement. In all cases leakage remains modest.

Contrary to previous assumptions, updating rules falls within the competence of policymakers: NAPs may include various forms of updating, or not at all. As highlighted by some authors, updating rules are not neutral. EB updating for example is often disqualified because it has perverse effects on investment (Neuhoff et al., 2006): it leads industrials to invest in plants more $\mathrm{CO}_{2}$ intensive than what is optimal. The two other rules, as we have seen in this subsection, differ concerning both competitiveness and environmental efficiency.

Concerning competitiveness, no updating leads to higher EBITDA (i.e. lower CRFA) and lower production than $\mathrm{OB}$ updating. By choosing between these two updating rules, policymakers favour one of the aspects of competitiveness. Interestingly, the fact that EBITDA rises less with OB updating is probably unexpected to industry lobbyists since most of them favour outputbased allocation (e.g., UNICE, 2002), which is a form of instantaneous OB updating. Yet it is consistent with other simulations (Burtraw et al., 2001, Demailly and Quirion, 2006).

Concerning environmental efficiency, $\mathrm{OB}$ updating leads to lower $\mathrm{CO}_{2}$ leakage. However, like output-based allocation, it raises the issue of compliance cost: by giving less incentive to reduce production, further unitary abatements are required to reach a given emission reduction which may be suboptimal (Fischer, 2001).

\section{Total range of uncertainty}

Up to now, we have varied only one parameter at a time to test the robustness of the qualitative results from our central scenario. In this section, we study every possible combination of parameters, i.e. $3^{5}=243$ combinations. Assuming that every set of parameters value has the same likelihood - which overestimates the variance, compared to an assumption of a higher probability for medium values - we use the IPCC terminology for handling uncertainty: "very likely" means at least a $90 \%$ probability and "likely" means at least a $2 / 3$ probability.

As in the central scenario, the impact of the EU ETS on the price of EU steel producers appears to be limited: in all cases, the rise is under 3.5\% - well under inter-annual variations (IISI, 2006a) while its mean value equals $2 \%$. 
This robustness stands for impacts on trade (it is very likely that EU exports drop by less than 5\% and EU imports increase by less than $7 \%$ ) and consumption ( $-2 \%$ at worst). Finally, it stands for production: in the worst case, the loss reaches $4 \%$ and it is very likely to stay under $2 \%$. The production impact is thus very likely to stay in the range of inter-annual fluctuations (Eurofer, 2006).

The central scenario forecasts a $1.5 \%$ rise for the EBITDA on production. Although the mean value across the $3^{5}$ scenarios is lower $(+0.5 \%)$, this variable increases with a probability of $60 \%$.

The CRFA is in a wide range of 11 to $114 \%$ of BaU emissions. Indeed, with the exception of the MACC assumption, all other assumptions have a significant impact on this output variable. If the pass-through assumption entails the highest variability, the updating rules assumption involves the highest CRFAs. The fact that pass-through values and updating rules are major assumptions calls for further investigation on these assumptions. In spite of this important variability, one may keep on thinking that the steel manufacturers have been overcompensated in the first NAPs: CRFA is likely to be under $90 \%$. Without updating, the CRFA is likely to be under $75 \%$.

Furthermore, even if fewer allowances were allocated for free, EBITDA loss would be modest: Allocating for free $50 \%$ of BaU emissions would at worst entail a 3\% drop in EBITDA, well in the range of inter-annual variations (OECD, 2005).

The emissions reduction varies from 5 to $21 \%$ of BaU emissions, with a median value of $12 \%$, as in the central scenario. For all sets of parameters, steel producers appear to be net sellers on the $\mathrm{CO}_{2}$ market for a free allocation of $95 \%$ of $\mathrm{BaU}$ emissions.

Although leakage varies considerably from 0.5 to $25 \%$, it has a relatively low median value, $6 \%$, and is very likely to be under $15 \%$ (recall that the upper range of economy-wide estimates is $20 \%$ ). The conclusion from the central scenario that the iron and steel sector does not seem especially sensitive to $\mathrm{CO}_{2}$ leakage turns out to be robust.

\section{Conclusions}

The goal of the paper was to assess the competitiveness impact and the environmental effectiveness of the EU ETS in the iron and steel sector, while testing the robustness of the results to key assumptions: marginal abatement cost curve, price elasticity of demand, price elasticity of trade, pass-through rates and allocation updating rules. We address two dimensions of competitiveness: production and profitability.

A first conclusion is that production losses are weak, which is in line with the other assessments of the EU ETS (Oberndorfer, 2006 and references therein). We prove this conclusion to be robust. Profitability measured by EBITDA (earnings before interests, tax, debt and amortization) obviously depends on the amount of allowances allocated for free. It turns out that it is also highly sensitive to most assumptions. However, given the amount allocated by National Allocation Plans in the first period of the ETS (2005-2007) and expected in second period NAPs, we show that EBITDA of EU steel makers is likely to rise. Furthermore, even if fewer allowances are allocated for free in the future, EBITDA loss would be modest: allocating for free $50 \%$ of $\mathrm{BaU}$ emissions would at worst entail a 3\% drop in EBITDA, well in the range of inter-annual variations (OECD, 2005).

Hence the competitiveness issue should not prevent hardening the environmental stringency of the ETS in the second period. Moreover in the steel sector a large part of the allowances may be auctioned without threatening the profitability of regulated firms.

Furthermore, if Member States reject updating, a much lower amount of allowances has to be given for free to maintain profitability. More generally, updating rules chosen by Member States matter. First, emissions-based updating should be avoided because it creates perverse investment incentives (Neuhoff et al., 2006). Second, compared to no updating, output-based updating has 
opposite effects on the two sides of competitiveness: it softens production losses, but reduces the likely EBITDA gains. Moreover, it reduces $\mathrm{CO}_{2}$ leakage but may increase the overall compliance cost.

Our systematic sensitivity analysis allows us to identify the important assumptions for every output variable. Concerning competitiveness, it is only the MAC curve that appears to be insignificant. The demand and trade elasticities assumptions play a more important role in the first aspect of competitiveness, production, compared with pass-through values and updating rules. The latter two are more crucial concerning profitability. As regards environmental efficiency, trade elasticity is of the utmost importance.

The role of our first three assumptions (MAC curve, price elasticity of demand and of trade) is well understood by applied modellers. Conversely, the pass-through rates are most often implicit and their implication for competitiveness scarcely debated. However, we argue, their inclusion turns out to be of major importance. Similarly, updating is seldom addressed: modellers typically assume a lump-sum allocation; an assumption in itself which is highly debatable. Inclusion of this assumption has drastic consequences for the competitiveness results of the models.

Thus, the pass-through rates and updating rules, although most often implicit and not debated in existing analyses, are of major importance. This calls for further empirical estimates of passthrough as well as further investigation on updating rules in all Member States NAPs and business expectations on these rules.

\section{Appendix A. Model parameters}

\begin{tabular}{|c|c|c|c|}
\hline Parameter & Description & Value & Source \\
\hline $\mathrm{ue}_{\mathrm{e}}^{0}$ & Direct unitary emissions in UE 15 & $\begin{array}{l}0.7 \mathrm{tCO}_{2} / \mathrm{t} \\
\text { steel }\end{array}$ & $\begin{array}{l}\text { IEA } \mathrm{CO}_{2} \text { emission database (2006); consistent with } \\
2005 \text { emissions covered by the EU ETS }\end{array}$ \\
\hline $\mathrm{ue}_{\mathrm{r}}^{0}$ & Direct unitary emissions in RoW & $\begin{array}{l}0.98 \mathrm{tCO}_{2} / \mathrm{t} \\
\text { steel }\end{array}$ & IEA $\mathrm{CO}_{2}$ emission database (2006) \\
\hline ue_elec $c_{\mathrm{e}}^{0}$ & $\begin{array}{l}\text { Emissions per kWh of electricity } \\
\text { in UE } 15\end{array}$ & $\begin{array}{l}385 \mathrm{~g} \mathrm{CO}_{2} / \\
\mathrm{kWh}\end{array}$ & IEA $\mathrm{CO}_{2}$ emission database (2006) \\
\hline ue_elec ${ }_{r}^{0}$ & $\begin{array}{l}\text { Emissions per kWh of electricity } \\
\text { in RoW }\end{array}$ & $\begin{array}{l}564 \mathrm{~g} \mathrm{CO}_{2} / \\
\mathrm{kWh}\end{array}$ & IEA $\mathrm{CO}_{2}$ emission database (2006) \\
\hline $\begin{array}{l}P_{\mathrm{ee}}^{0}, P_{\mathrm{er}}^{0}, P_{\mathrm{re}}^{0}, \\
P_{\mathrm{rr}}^{0}\end{array}$ & Steel prices 2001 & 538 euros/t & Computation based on ECSC and Eurostat (2003) \\
\hline$Q_{\mathrm{e}}^{0}$ & EU 15 production 2001 & $158 \mathrm{Mt}$ & ECSC and Eurostat (2003) \\
\hline$Q_{\mathrm{re}}^{0}$ & $\begin{array}{l}\text { Imports (excluding intra-EU trade) } \\
2001\end{array}$ & $21.2 \mathrm{Mt}$ & \\
\hline$Q_{\mathrm{er}}^{0}$ & $\begin{array}{l}\text { Exports (excluding intra-EU trade) } \\
2001\end{array}$ & $20.3 \mathrm{Mt}$ & \\
\hline$Q_{\mathrm{r}}^{0}$ & RoW production 2001 & $667 \mathrm{Mt}$ & IISI (2006b) \\
\hline el_EAF $\mathrm{EF}_{\mathrm{e}}^{0}$ & $\begin{array}{l}\text { Unitary electricity consumption } \\
\text { (electric arc furnace) }\end{array}$ & $\begin{array}{l}0.65 \mathrm{MWh} / \mathrm{t} \\
\text { steel }\end{array}$ & Computation based on Reinaud (2004) \\
\hline el_BOF ${ }_{\mathrm{e}}^{0}$ & $\begin{array}{l}\text { Unitary electricity consumption } \\
\text { (basic oxygen furnace) }\end{array}$ & $\begin{array}{l}0.25 \mathrm{MWh} / \mathrm{t} \\
\text { steel }\end{array}$ & Computation based on Reinaud (2004) \\
\hline
\end{tabular}

\section{References}

Åhman, M., Burtraw, D., Kruger, J.A., Zetterberg, L., 2005. The ten-year rule: allocation of emissions allowances in the EU emissions trading system. RFF Discussion Paper, vol. 05-30.

Bernard, A., Vielle, M., Viguier, L., 2006. Premières simulations de la directive européenne sur les quotas d'émissions avec le modèle GEMINI-E3. Economie et Prévision 169-171. 
Blok, K., de Jager, D., Hendriks, C., Kouvaritakis, N., Mantzos, L., 2001. Economic evaluation of sectoral emission reduction objectives for climate change - comparison of top-down and bottom-up analysis of emission reduction opportunities for $\mathrm{CO}_{2}$ in the European Union. Ecofys, AEA and NTUA, Report for European Commission, DG Environment, Brussels, September.

Böhringer, C., Hoffmann, T., Manrique-de-Lara-Penãte, C., 2006. The efficiency costs of separating carbon markets under the EU emissions trading scheme: a quantitative assessment for Germany. Energy Economics 28, 44-61.

Burtraw, D., Palmer, K., Bharvirkar, R., Paul, A., 2001. The effect of allowance allocation on the cost of carbon emission trading. RFF Discussion Paper 01-30, Washington D.C., the U.S.

CDC [Caisse des Dépôts et Consignations], 2006. Panorama des Plans Nationaux d'Allocation des Quotas en Europe. Note d'étude ${ }^{\circ} 8$ de la Mission climat de la Caisse des Dépôts.

Demailly, D., Quirion, P., 2006. $\mathrm{CO}_{2}$ abatement, competitiveness and leakage in the European Cement Industry under the EU ETS: grandfathering versus output-based allocation. Climate Policy 6 (1), 93-113.

ECSC, Eurostat, 2003. Iron and steel yearly statistics. Concluding edition, data 1993-2002.

Erkel-Rousse, H., Mirza, D., 2002. Import price-elasticities: reconsidering the evidence. Canadian Journal of Economics 35 (2).

Eurofer, 2006. EU crude steel production statistics. Available at http://www.eurofer.org/cgi-bin/year_crude_production. pl? earCrude $=2002$.

Fischer, C., 2001. Rebating environmental policy revenues: output-based allocations and tradable performance standards. RFF Discussion paper, vol. 01-22. The U.S, Washington D.C.

Fouquin, M., Sekkat, K., Mansour, J., Mulder, N., Nayman, L., 2001. Sector sensitivity to exchange rate fluctuations. CEPII Working Paper, vol. 11. November, Paris.

France, MEDD [ministère de l'Ecologie et du Développement durable], 2006. Projet de plan national d'affectation des quotas d'émission de gaz à effet de serre, version du 23 juin 2006. Available at http://www.consultationpubliquepnaq. com/download/PNAQII_23juin2006.pdf.

Gielen, D., Moriguchi, Y., 2002. $\mathrm{CO}_{2}$ in the iron and steel industry: an analysis of Japanese emission reduction potentials. Energy Policy 30, 849-863.

Hidalgo, I., Szabo, L., Ciscar, J.C, Soria, A., 2003. $\mathrm{CO}_{2}$ emission trading within the iron and steel industry: a world simulation model. IPTS, Sevilla, Spain. March.

Hourcade, J.-C., Shukla, P., 2001. Global, Regional, and National Costs and Ancillary Benefits of Mitigation. Chap. 8 in Climate Change 2001. IPCC Third Assessment Report, Cambridge UP.

IISI [International Iron and Steel Institute], 2006a. World Steel 2006 in Figures.

IISI [International Iron and Steel Institute], 2006b. Steel statistic archive 2001. available at http://www.worldsteel.org/ ?action $=$ stats \& type $=$ steel\&period=year\&year $=2001$.

Kee, H.L., Nicita, A., Olarreaga, M., 2004. Import demand elasticities and trade distortions. Centre for Economic Policy Research. Discussion Paper No, vol. 4669.

Kitous, A., 2002. Personal communication.

Klepper, G., Peterson, S., 2004. The EU Emissions Trading Scheme: allowance prices, trade flows, competitiveness effects. FEEM Working Paper, vol. 49.

Klepper, G., Peterson, S., 2006. Emissions trading, CDM, JI, and more: the climate strategy of the EU. Energy Journal 27 (2).

Krugman, P., 1994. Competitiveness: a dangerous obsession. Foreign Affairs 73 (2).

Lord, R., Ken Farr, W., 2003. Collusion and financial leverage: an analysis of the integrated mill steel industry. Financial Management, Financial Management Association 32 (1) (Spring).

Neuhoff, K., Keats, K., Sato, M., 2006. Allocation, incentives and distorsions: the impact of EU ETS emissions allowance allocation to the electricity sector. Climate Policy 6 (1), 73-91.

Oberndorfer, U., 2006. The impacts of the European Emissions Trading Scheme on Competitiveness and Employment in Europe - a Literature Review. Report commissioned by WWF.

OECD, 2002. Environmental policy in the steel industry: using economic instruments. Report for the Joint Meeting of Tax and Environment Experts, Paris.

OECD, 2005. STAN database. available at: http://www.oecd.org/document/15/0,2340,en_2649_201185_1895503_1_1_1_1,0. $\mathrm{html}$.

Oxera, 2004. The European Emissions Trading Scheme: implications for industrial competitiveness. Report for the Carbon Trust.

Quirion, P., Hourcade, J.-C., 2004. Does the $\mathrm{CO}_{2}$ emission trading directive threaten the competitiveness of European industry? Quantification and comparison to exchange rates fluctuations. EAERE, Annual Conference, Budapest.

Reilly, J.M., Paltsev, S., 2005. An analysis of the European Emission Trading Scheme. MIT, Joint Program on the Science and Policy of Global Change Report No, vol. 127. 
Reinaud, J., 2004. Industrial competitiveness under the European Union Emissions Trading Scheme. IEA Information Paper.

Schleich, J., Betz, R., 2005. Incentives for energy efficiency and innovation in the European Emission Trading System. Proceedings of the ECEEE Summer Study, Mandelieu. available at http://www.eceee.org/library_links/proceedings/ 2005/abstract/7124schleich.lasso.

Sijm, J.P.M., Neuhoff, K., Chen, Y., 2006. $\mathrm{CO}_{2}$ cost pass-through and windfall profits in the power sector. Climate Policy 6 (1), 49-72.

Sijm, J.P.M., Smekens, K.E.I., Kram, T., Boots, M.G., 2002. Economic Effects of Grandfathering $\mathrm{CO}_{2}$ Emission Allowances. ECN, The Netherlands. April.

Smale, R., Hartley, M., Hepburn, C., Ward, J., Grubb, M., 2006. The impact of $\mathrm{CO}_{2}$ emissions trading on firm profits and market prices. Climate Policy 6 (1), 31-48.

Stennek, J., Verboven, F., 2001. Merger control and enterprise competitiveness: empirical analysis and policy recommendations. European Economy. European Commission Directorate-General for Economic and Financial Affairs, No, vol. 5, pp. 129-194.

UNICE, 2002. Comments on the Proposal for a Framework Directive for EU Emissions Trading. 25 February, Brussels.

Winters, A.L., 1995. Liberalising European steel trade. European Economic Review 39, 611-621. 